\title{
O ALTO CAMAQUÃ E A PECUÁRIA FAMILIAR: A CONSTRUÇÃO DA EDUCAÇÃO AMBIENTAL HÍDRICA
}

\author{
Cibelle Machado Carvalho ${ }^{1}$ \\ Nájila da Souza Rocha² \\ Rafael Cabral Cruz ${ }^{3}$
}

Resumo: O território do Alto Camaquã/RS tem como aspecto fundamental a pecuária familiar e sua dependência com os recursos naturais. Porém, há restrições, como baixas disponibilidades hídricas e alterações nas nascentes. Partindo deste princípio, para modificar tal realidade e desenvolver estratégias de Educação Ambiental (EA) é necessário conhecer a realidade e as representações sociais dos pecuaristas familiares. A análise dos resultados propiciou identificar as potencialidades e dificuldades perante metodologias de EA, posteriormente foram diagnosticadas as ideias e percepções, representações dos pecuaristas sobre manejo de campo e água, escassez hídrica, água e qualidade de vida e a sua influência na produção.

Palavras-chave: Representação Social; Educação Ambiental Hídrica; Pecuária Familiar; Alto Camaquã.

\footnotetext{
${ }^{1}$ Doutoranda em Engenharia Civil- Recursos Hídricos e Saneamento. Universidade Federal de Santa Maria. E-mail: cibelle mc@yahoo.com.br

2 Doutoranda em Sensoriamento Remoto. Universidade Federal do Rio Grande do Sul. E-mail: najila.rocha2011@gmail.com

${ }^{3}$ Orientador. Doutor em Ecologia. Universidade Federal do Pampa. E-mail: rafaelcabralcruz@gmail.com
} 


\section{Introdução}

As assimetrias em relação ao desenvolvimento econômico e social do Rio Grande do Sul (RS) tem distinções diferentes. A Metade Sul (MS) apresenta-se como uma região em processo de estagnação, enquadrada em programas de desenvolvimento regional, em âmbito nacional (MATEI; FILIPPI, 2012). Na conjuntura das desigualdades regionais, a MS apresenta um predomínio de latifúndios orizícolas e pecuária extensiva. Já o desenvolvimento da Metade Norte foi caracterizado por pequenas e médias propriedades que foram a base para a presença de indústrias e, consequentemente, das grandes concentrações urbanas.

A MS tem uma realidade diferenciada em termos de estrutura fundiária e formação cultural, sendo uma região com pouca ou nenhuma expressão de pecuária ou agricultura familiar. Porém, há estudos na região da Serra do Sudeste demonstrando a diversidade e heterogeneidade das formas de ocupação da parte sul do RS. A agricultura e pecuária familiar se mesclam em pequenas áreas ocupadas, quase que exclusivamente, por mão de obra familiar (BORBA, 2002; MATTE, 2013; NESKE, 2009).

Azevedo e Fialho (2016) afirmam que as características familiares desta região e aspectos culturais produziram um tipo diferenciado de agricultor familiar, historicamente invisível e não reconhecido, identificado como "pecuarista familiar".

Em particular, o Alto Camaquã, inserido na Metade Sul/RS e Serra do Sudeste, área de estudo desta pesquisa, é um território composto por uma notória beleza do bioma Pampa, com aflorações rochosas, vales, plantas endêmicas e com pouca degradação ambiental, rara beleza paisagística, além de solos rasos e pedregosos, pouco produtivos no contexto da agricultura (DADALT, 2010; TRINDADE et al., 2010). Os mesmos autores afirmam que esse território não se transformou em agricultura tradicional nem em agricultura moderna, e se manteve com uma alta dependência dos recursos naturais disponíveis.

Isso se deve, principalmente, ao seu aspecto geológico, pois domina um sistema aquífero limitado de baixa produção de água (aquitardos), em rochas de porosidade intergranular ou fraturadas (CPRM, 2005). Ou seja, a construção de poços tubulares não seria a melhor alternativa para 0 abastecimento humano e dessedentação de animais. Rocha (2016), em sua dissertação, afirma que a baixa resistência dos solos, falta de alternativas para a permanência dos pecuaristas familiares no território, além de baixas disponibilidades hídricas, são os principais fatores de aumento da fragilidade e vulnerabilidade dos pecuaristas familiares do Alto Camaquã.

Carvalho et al. (2015), estudando o uso de águas de nascentes no mesmo território, observaram que a disponibilidade de água é escassa ou mal gerenciada. Verificaram-se que as nascentes difusas são as mais impactadas em função da dessedentação animal. 
Carvalho (2015) afirma que o Comitê de Gerenciamento de Bacias Hidrográficas do Rio Camaquã demonstrou invisibilidade ao território e aos atores sociais que o contemplam, devido, principalmente, à pouca importância econômica regional. Em contrapartida, as formas de relação com a natureza constituem-se como um conjunto de conhecimentos herdados em um processo coevolucionário e que é ainda possível encontrar nas unidades familiares uma racionalidade ecológica (NESCK, 2009).

Azevedo e Fialho (2016) afirmam que os agricultores identificados como atrasados no final da década de 1950 começam a auferir certa consideração através de um novo conceito de etnoecologia - que valoriza o conhecimento ecológico local.

Porém, a ausência de um sistema público de distribuição de água e a cultura local faz com que a população rural do Alto Camaquã utilize, ao longo dos anos, as nascentes como fonte de água para subsistência e abastecimento no território, ou seja, utilizando as cacimbas como forma adaptativa para superar esse problema (CARVALHO et al. 2014; 2015).

Matte (2013), em sua pesquisa, identificou que $72 \%$ dos pecuaristas do Alto Camaquã entrevistados sofrem com restrição de uso na quantidade de água e muitos não dispõem dos ativos necessários para enfrentar essa situação de vulnerabilidade.

A dificuldade de disponibilidade hídrica envolve a mobilização de capital físico, de capital financeiro e capital social dos pecuaristas familiares, que buscam se adaptar à situação. Dentre as estratégias de adaptação estão investimentos em melhoria das fontes de água existentes, principalmente, a melhoria nas cacimbas que são aprofundadas no intuito de obter maior captação de água (MATTE, 2013).

A construção de reservatórios junto às nascentes foi a solução encontrada pelos pecuaristas familiares ao longo de 150 anos de ocupação deste território, as "cacimbas" ou reservatórios não estabelecem um padrão e são construídas de acordo com os recursos financeiros e conhecimento empírico, além do alcance da funcionalidade desejada para o sistema de captação e distribuição de água (CARVALHO et al., 2015).

Rocha (2016) salienta que o déficit hídrico é o agente causador das vulnerabilidades da pecuária familiar, portanto, ações estruturais, não estruturais e a gestão de recursos hídricos, com o objetivo de mitigar os efeitos da falta de água, devem ser prioridades nas políticas públicas. A autora ainda afirma que os pecuaristas são mais vulneráveis por dependerem exclusivamente dos recursos hídricos naturais (precipitação) e não apresentarem alternativas para minimizar essa dependência.

Carvalho et al. (2015) afirmam que as irregularidades das precipitações, dificuldades de captação, distribuição e uso da água, supressão da vegetação, depósito de lixo doméstico em zonas de recarga e o uso de nascentes como bebedouros de animais estão entre os principais problemas identificados. A 
qualidade e quantidade das águas das nascentes da bacia hidrográfica estão sendo alteradas por fatores antrópicos.

Os conflitos hídricos existentes no território do Alto Camaquã demonstram a necessidade de abordar políticas, estratégias e diagnosticar a área para projetos mais eficazes de educação ambiental hídrica, obtendo resultados mais concisos para uma população que se utiliza predominantemente da água das nascentes. A importância dos recursos naturais potencializa a busca e a construção de estratégias duráveis de gestão e metodologias de educação de recursos hídricos.

Partindo deste princípio, a Política Nacional da Educação AmbientalPNEA, entende que a educação ambiental é um processo por meio do qual o indivíduo e a coletividade constroem valores sociais, conhecimentos, habilidades, atitudes e competências voltadas para a conservação do meio ambiente, bem de uso comum do povo, essencial à sadia qualidade de vida e sua sustentabilidade (BRASIL, 1999).

Marinato (2008) discute que para alcançar o objetivo de ordenamento territorial a partir de uma relação harmônica entre o meio ambiente e os assentamentos humanos, com 0 propósito de diminuir as desigualdades regionais e alcançar um desenvolvimento socialmente equilibrado, respeitando o ambiente natural, é necessário pensar que a relação ser humano-ambiente não se define através de generalizações macros, mas em uma escala de relevância imediata, a escala local.

Nesse contexto, o objetivo geral norteador deste estudo é diagnosticar e estudar as representações sociais das pecuaristas familiares do Alto Camaquã quanto aos recursos hídricos. Interessa conhecer seus processos perceptivos e imaginários em um contexto cultural, visando conhecer seus valores, ideias e práticas, para que se possa proporcionar uma educação ambiental hídrica adequada para famílias de pecuaristas familiares, enfatizando o gerenciamento do uso, distribuição, captação e tratamento doméstico do recurso hídrico. Com isso, pode-se, também, re-conhecer seu âmbito e seu potencial natural, humano e produtivo para uma melhor eficiência da educação ambiental com ênfase no uso da água, minimizando, assim, a intensidade do impacto causado pela escassez do recurso hídrico na pecuária familiar.

\section{As representações sociais para a construção da educação ambiental não formal}

Conhecimentos construídos pelas relações do ser humano com o seu ambiente são considerados representações sociais, e estas estão relacionadas às crenças, elementos simbólicos, ideias, valores, imagens que os indivíduos expressam mediante palavras e gestos, utilizando-se da linguagem oral ou escrita, explicitando o que pensam ou percebem, nessa ou aquela situação, no qual o comportamento é parte do conteúdo da própria representação social e consequência do comportamento que é conectado à ação do homem (MOSCOVICl, 2011).

Revbea, São Paulo, V. 14, № 1: 149-170, 2019. 
As representações sociais são originárias do senso comum que um grupo social ou indivíduo tem sobre determinado tema, desta forma são constituídas ideologias, preconceitos e características cotidianas, sociais e profissionais (REIGOTA, 2002).

O desenvolvimento gradativo para a construção da educação ambiental em um meio ambiente, tem de estar atrelado a essas relações de senso comum, que estão sempre em constantes mutações, uma vez que somos produtos das nossas crenças, valores, ideias que estão sempre em mudanças devido ao amadurecimento humano pelo contato cultural e trocas dialógicas.

As representações sociais podem ser definidas como "imagens construídas sobre o real" (MINAYO, 2004). Portanto, representação é um conjunto de conceitos, propostas e explicações que surgem na vida cotidiana, em um processo de comunicação interpessoal (MOSCOVICl, 2011). Estudos em representações sociais são conhecimentos construídos pelas relações do ser humano com o seu ambiente (REIS; BELLINI, 2011).

A teoria das representações sociais sobre a produção dos saberes sociais se refere a qualquer saber, mas a teoria está especialmente dirigida aos saberes que se produzem no cotidiano, e que pertencem ao mundo vivido (GUARESCHI; JOVCHELOVITCH, 1995).

Freire (1984) afirma que a psicologia social é uma ferramenta para um desenvolvimento com educação. A representação social de indivíduos ou grupos é necessária para entender como os agentes sociais estão captando e interpretando as questões ambientais e, principalmente, como pensam e agem em situações concretas de sua realidade.

A educação não formal é a construção das concepções pedagógicas em um contexto onde está inserido o grupo social (SEVERO, 2016). Desta maneira, o primeiro passo para a realização da educação ambiental não formal é a identificação das "representações" dos pecuaristas familiares envolvidos no processo e problemática explanada.

Trevisol e Socolovsky (2000) afirmam que um dos objetivos fundamentais da educação ambiental é criar situações em que os indivíduos se sintam estimulados a rever seu modo de conceber o meio ambiente e sua relação com ele. Vale salientar que todo o trabalho advindo da educação ambiental é uma tentativa de intervir com as representações sociais, reforçando aspectos potencializadores e transformando os negativos.

Portanto é necessário indicar o que é realmente efetivo, mudar o que é realmente necessário e reforçar o que é preciso. Nessa perspectiva, o meio ambiente é um eco-sócio-sistema, caracterizado pela interação entre seus componentes biofísicos e sociais. 


\section{Descrição e caracterização da área de estudo}

O território do Alto Camaquã está localizado na Serra do Sudeste/RS, região do Escudo Cristalino Sul-Rio-Grandense, à montante da Bacia Hidrográfica do Rio Camaquã (TRINDADE et al., 2010), corresponde ao terço superior da bacia. Os municípios que envolvem o território são os municípios de Bagé, Pinheiro Machado, Piratini e Canguçu na margem direita e Lavras do Sul, Caçapava do Sul, Santana da Boa Vista e Encruzilhada do Sul pela margem esquerda do Rio Camaquã. O Alto Camaquã, situa-se nas coordenadas geográficas $30^{\circ} 25^{\prime}$ a $31^{\circ} 33^{\prime}$ de latitude sul e $52^{\circ} 48^{\prime \prime}$ a $54^{0} 12^{\prime}$ de longitude oeste (Figura 1).

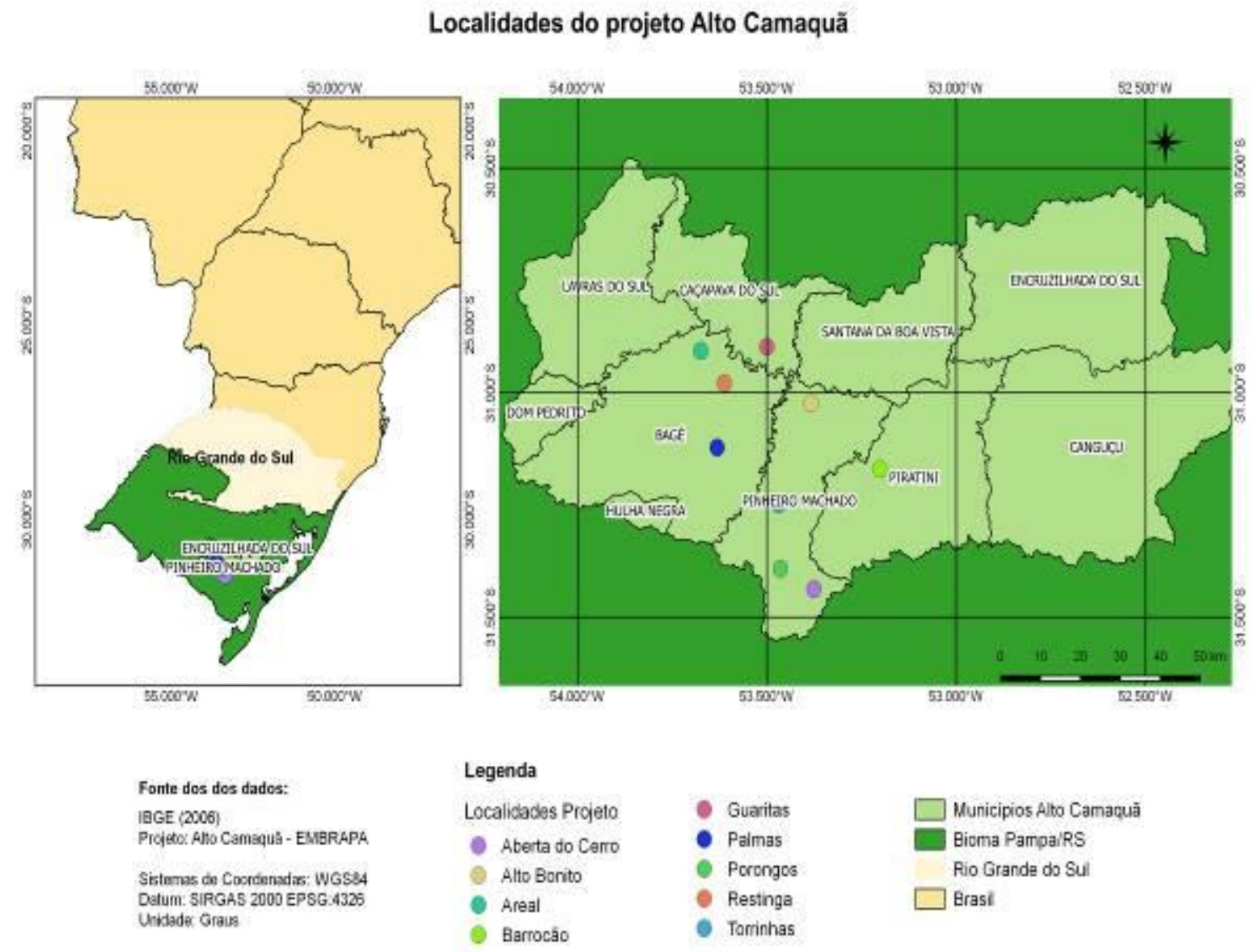

Figura 1: Mapa de localização dos distritos e localidades estudados do território do Alto Camaquã terço superior da Bacia Hidrográfica do Rio Camaquã. Fonte: Autores, 2019.

A concepção do conceito de território utilizada nesta pesquisa é a referência empírica do território do Alto Camaquã. Para isso considerou-se a delimitação política-administrativa e análise da distribuição de áreas Revbea, São Paulo, V. 14, № 1: 149-170, 2019. 
consideradas pelo Ministério do Meio Ambiente como de prioridade extremamente alta para conservação da biodiversidade, com pastagens naturais, com dominância nas microrregiões do Médio Superior e Alto Camaquã (BORBA, 2002), para, então, vincular as demais dimensões que compõem a integração do território.

Borba (2016) afirma que a impossibilidade de adoção de modelos produtivos modernos havia levado à estigmatização desta região como subdesenvolvida (estigma preconceituoso que se retroalimenta constantemente da incapacidade de criação de alternativas de desenvolvimento). Mas o mesmo autor salienta que, ao se analisar em uma perspectiva sistêmica, integrando dimensões sociais, culturais e ambientais, se encontrariam estratégias produtivas com a produção "ecológica", visto que os pecuaristas familiares dependem mais dos recursos naturais e energias renováveis do que de recursos mobilizados a partir do mercado, justificando este estudo.

\section{Estratégias metodológicas}

Utilizaram-se métodos de pesquisa qualitativa para este trabalho. A escolha dessa abordagem justifica-se em razão da problemática da pesquisa e da amplitude do problema social, assim, favorece aos pesquisadores a descrição e complexidade dos problemas diagnosticados, compreendendo as dinâmicas vividas pelos campos sociais e suas particularidades (RICHARDSON, 1999).

O alicerce dos objetivos traçados exigiu exploração e tratamento de entrevistas com os atores sociais, que está estabelecido no foco de estudo: entender os saberes sociais e diagnosticar as representações sociais dos pecuaristas familiares do Alto Camaquã no contexto dos recursos hídrico para que se possa proporcionar uma educação ambiental adequada.

Primeiramente, seguindo as recomendações de Minayo (2004), buscouse aproximação com as pessoas da área de estudo. Além disso, seguiram-se três princípios metodológicos propostos por Callon (1986) e Latour (2000), o agnosticismo, ou seja, não privilegiar nenhum ponto de vista; assimetria generalizada, que os pesquisadores devem considerar que as controvérsias são parte das relações humanas da sociedade e meio ambiente e por último, associação livre, os pesquisadores devem abandonar toda distinção a priori.

A pesquisa qualitativa não se baseia no critério numérico para garantir representatividade, assim, a amostragem boa é aquela que possibilita abranger a totalidade do problema investigado em suas múltiplas dimensões (MINAYO, 2004).

Utilizou-se o método da pesquisa social qualitativa (MINAYO, 2004), a orientação exploratória (GIL, 2006) e as teorias das representações sociais (MOSCOVICI, 2011). Centrando-se na análise da construção e transformação do conhecimento social a fim de elucidar como a ação e o pensamento interligam-se na dinâmica social.

revista brasileira educação ambiental 
Foram aplicados 20 roteiros de entrevistas, constituídos de 21 perguntas abertas. A escolha do roteiro semiestruturado para entrevista se justifica, na medida em que a ferramenta conduz para a identificação de representações da realidade, com liberdade para inclusão de temas e expressão de opiniões pelo entrevistado.

Para a realização desta pesquisa foram escolhidos os municípios de Pinheiro Machado (nos distritos de Restinga, Aberta do Cerro, Alto Bonito, Areal, Torrinhas e Porongos), Piratini (distrito do Barrocão), Bagé (distrito de Palmas) e Caçapava (distrito das Guaritas). Essa escolha se justifica pela presença mais intensa de pecuaristas familiares na Bacia Hidrográfica do Rio Camaquã.

O critério mais importante de amostragem é a identificação do "universo" de representações, as entrevistas foram realizadas até o ponto em que obtivessem suficiência amostral, ou seja, uma saturação de "ideias" na medida em que novas entrevistas eram realizadas e os resultados se repetiam (MINAYO, 2004). A escolha não aleatória pressupõe que os indivíduos sejam intencionalmente selecionados para o estudo proposto (CRESWELL, 2010). Todas as entrevistas foram realizadas no ano de 2015/2016, a demora nas expedições de campo se deu pela má logística e estradas de difícil acesso.

Vale mencionar que o roteiro de entrevista deve ser tratado e analisado, antes das saídas a campo. Para melhor sequência na elaboração de diário de campo foi realizado uma pilotagem do roteiro de entrevista para sua melhor aplicabilidade..

As entrevistas foram gravadas e posteriormente transcritas na íntegra, assim, essas transcrições viabilizaram a análise das informações a partir da técnica de análise de conteúdo e temática categorial (BARDIN, 1978).

As informações foram organizadas e tabuladas no programa Microsoft Office Excel, sendo sua análise distinta naquilo que confere à qualidade dos dados, realizando a interpretação, a explicação e a especificação das ideias e da relação entre elas (CARVALHO, 2015). Em um primeiro momento, foram transcritas as entrevistas, sendo organizadas com as respectivas perguntas e objetivos, posteriormente, foram relidas para um panorama geral da pesquisa e a terceira etapa consistiu na categorização das respostas, consistindo em um processo de organização do material.

Desenvolver com técnicas de categorias, permite uma descrição exata das características pertinentes ao conteúdo expresso no texto. Este tem por objetivo captar, descrever e analisar as percepções dos atores sociais envolvidos na entrevista (MOSCOVICI, 2011).

Matte (2013) afirma que uma forma de complementar a análise é utilizar as narrativas dos discursos, fotos captadas durante a expedição a campo como adjunto às discussões, complementando a análise, assim, confirmando os resultados. 


\section{Resultados e discussões}

Pesquisas recentes têm apontado indícios de que os pecuaristas do território do Alto Camaquã vêm enfrentando dificuldades nos últimos anos, o que nos dá pistas da presença de fatores que podem levar esses indivíduos e suas famílias a situações vulneráveis (RIBEIRO, 2009; NESKE 2009; MATTE, 2013). No entanto, com metodologias e estratégias a partir de suas representações sociais, pode-se construir medidas mitigadoras e amenizar os índices de vulnerabilidades.

\section{Potencialidades para a construção da Educação não formal Hídrica}

Na visão de Guimarães (2004), um ambiente educativo deve oportunizar o conhecer, sentir, experimentar, vivenciar (aspectos afetivos), estimular a reflexão e a ação em sua complementaridade, motivar uma postura problematizadora que potencialize o surgimento de novos valores e atitudes individuais, coletivas e construir novos conhecimentos dos saberes.

A educação ambiental deve estar pautada na visão de um ambiente por inteiro, isto é, considerando a interdependência sistêmica entre o meio natural e o construído, sempre respeitando os fatores históricos, culturais e sociais dos envolvidos. A educação ambiental hídrica atuará na gestão de conflitos no território do Alto Camaquã e dos usos distributivos dos recursos naturais.

Um dos primeiros aspectos potencializadores é que todos os entrevistados percebem a relação da qualidade do solo, planta e animal em sua experiência cotidiana e contextualizam como um sistema vivo, no qual, um depende do outro para sua sobrevivência. No entanto, ainda carecem de contextualização, para atrelar o conhecimento para a educação ambiental, como exemplo segue a resposta dos atores sociais:

\footnotetext{
Entrevistado 03: "Sim, um depende do outro né".

Entrevistado 15: "A natureza é muita perfeita, acho que sim, se associa uma coisa com a outra, penso eu".
}

Visando estratégias de desenvolvimento rural atualmente em curso no território, há geração de novos conhecimentos em um contexto de formação e fortalecimento de redes sócio-técnicas envolvendo ações coletivas dos pecuaristas familiares (NESKE, 2009). Individualmente, os pecuaristas, atrelados ao empírico, percebem a dependência e a interligação do solo, planta e animal, no entanto não conseguem entender os impactos positivos e negativos dessas interligações, partindo deste princípio, é um aspecto potencializador por entenderem esse ciclo. 
Os pecuaristas percebem a potencialidade do manejo de campo. $70 \%$ dos respondentes afirmaram que um campo continuado dessa prática é o melhor caminho.

Entrevistado 1: "eu acho que o sistema rotativo é muito bom. é eu acho que é muito bom".

Entrevistado19: "É a subdivisão. Daí vo ter um campo e pasto de maior qualidade".

Entrevistado 23: "manter ele alto e fazer a rotação de potreiros e fazer o possível pra ele melhorar né".

A maioria dos respondentes (70\%) percebe que a capacidade do solo de absorver a água está nas ideias de vegetação alta, e o principal fator de impedimento da água infiltrar são áreas compactadas e campo "rapado". No entanto, alguns ainda percebem que o impedimento da água é culpa de grandes enxurradas de chuva, ou seja, não tem tempo suficiente para o solo absorver a água, além de culparem grandes proporções de rochas.

Entrevistado 5: "eu acho que esse negócio de lavra a terra acho que judia da terra".

Entrevistado 20: "o que não absorveu, o que afeta é a compactação da terra, se a terra ta sem cobertura ai ela escorre mesmo ne, ai escorre".

A grande maioria dos respondentes percebe que o principal fator de restrição é o solo degradado. Um aspecto interessante é que grande parte dos pecuaristas pagaria para ter água em abundância em sua propriedade, ou seja, alocaria recursos financeiros para a proteção das nascentes, mesmo que seja uma realidade cultural não vivenciada, como em áreas urbanas. Essa realidade é uma valoração ambiental muito associada as suas dificuldades diárias.

Entrevistado 24: "Ah pagaria. Se eu tivesse condição conforme a minha necessidade da água pagava. Ah eu ganho um salário né, até uns 120 pila eu pagava. A principal fonte da nossa vida é a água, para nós para os animais, as planta, tudo".

Entrevistado 7: "Acho que sim, o que eu tivesse condições de paga, pra ter água em abundância? 2.000 mil, 3.000 mil reais por ano, sei lá, valeria se fosse em abundância". 
A água não foi considerada diretamente um limitador nos fatores de produção, os respondentes agregaram o fator genético, experiência no campo, manejos adequados e clima. Assim tornando-se metodologias de educação ambiental mais viáveis a partir da gestão ambiental da propriedade.

Nos atributos naturais, $41,6 \%$ dos respondentes consideram o campo, pastagem, e saúde animal os atributos essenciais para vender um animal de boa qualidade para a indústria. Os fatores que podem ser trabalhados com uma metodologia de educação ambiental é o manejo, no entanto não, os respondentes não atribuem a água como essencial para esse ciclo. Metade dos entrevistados percebe a importância e influência da escolha do local para a eliminação dos resíduos sólidos, os outros $45 \%$ queimam os resíduos em sua propriedade.

\section{Dificuldades para a construção da Educação não formal hídrica}

O primeiro aspecto justificador atrelado à dificuldade é a descrição do tipo de campo bom que rende mais por hectare. Esse tem o objetivo de identificar a primeira imagem que é manifestada pelo respondente, juntamente com a representação social da capacidade de carga e o manejo que produzem em sua propriedade.

A maioria dos entrevistados não percebe a forma diferenciada dos seus serviços ambientais prestados e o mínimo grau de modificação dos seus campos sendo primordial e determinante para a manutenção, produtividade e conservação do meio em que vivem como um todo.

Os respondentes percebem como um campo bom aquele que advêm com menor quantidade de "mato" e "pedras", além de campos planos e grandes quantidades de água. No entanto, quatro pecuaristas responderam que o campo depende do tipo de manejo que se pratica. Assim, manifesta-se a dificuldade de perceberem 0 ambiente em que vivem, com suas belezas cênicas e vales rochosos, principalmente por não atribuir um retorno econômico.

Outra dificuldade encontrada é que os respondentes representam e percebem que, para um campo continuar bom e melhorar, há necessidade de limpeza contínua no campo além do manejo, ou seja, ainda não perceberam a grande quantidade de espécies de gramíneas em seus campos.

$\mathrm{Na}$ pesquisa realizada por Matte (2013), foi constatado que o campo nativo imprime algum grau de vulnerabilidade em situações específicas (ex. baixa disponibilidade de pastagens no período de inverno), já que os sistemas produtivos praticados estão adaptados às suas condições.

Os praticantes de manejo de campo atribuíram grandes dificuldades para que seu manejo continue melhorando, como falta de mão de obra, limpeza, aumento da área manejada e principalmente falta de chuva. 
Outro aspecto dificultador é que os pecuaristas não percebem que são manejadores do ambiente, não se representam como parte do ambiente em que vivem e que o gerenciamento da água da propriedade é feito pelo próprio pecuarista. A visão de escoamento superficial é limitada, no sentido de não perceberem que o manejo de campo e o grande receptor de água da chuva.

\footnotetext{
Entrevistado 11: "pensaria numa maneira que eu pudesse armazenar ela, segura ela dentro da propriedade pra ela não fugi".

Entrevistado 13: "praticamente perdida aquela chuva ne".

Entrevistado 24: "pensaria numa maneira que eu pudesse armazenar ela, segura ela dentro da propriedade pra ela não fugi".
}

A grande vulnerabilidade dos pecuaristas são os problemas de escassez recorrentes, principalmente no verão, e a inexistência de estratégias para essa problemática.

Portanto, as metodologias de educação ambiental terão ênfase nos critérios de maior dificuldade. Segundo Dias (2004), a educação ambiental é considerada um processo permanente, no qual os indivíduos e a comunidade tomam consciência do meio ambiente e adquirem os conhecimentos, os valores, as habilidades, as experiências e a determinação que os tornam aptos a agir individual e coletivamente para resolver problemas ambientais presentes e futuros.

\section{Contextualizações do espaço empírico: as representações sociais no contexto água para a construção de estratégias de metodologias de educação}

Quanto à perspectiva do meio ambiente, a Representação Social de indivíduos ou grupos é necessária para entender como os agentes sociais estão captando e interpretando as questões ambientais e, principalmente, como pensam e agem em situações concretas de sua realidade.

O primeiro passo, para a realização da Educação Ambiental deve ser a identificação das "representações" dos pecuaristas familiares envolvidas no processo educativo. Como afirmam Trevisol e Socolovsky (2000), um dos objetivos fundamentais da Educação Ambiental é criar situações nas quais os indivíduos se sintam estimulados a rever seu modo de conceber o meio ambiente e sua relação com ele.

As respostas dos participantes foram agrupadas em cinco categorias: 


\section{Categoria 1: Características e contextos no manejo do campo}

Todos os respondentes percebem a relação do solo, planta e animal, e sua dependência um do outro conforme já relatamos nesta seção de resultados. Porém, a maioria não percebe a água como primordial para esse sistema vivo.

As principais ideias ligadas a esta categoria são: sobrevivência (15)4, ciclo (6), integração (8) e produção (5). A percepção de sobrevivência está encadeada na ideia de que o solo, planta e animal não sobrevivem um sem o outro, no entanto, os respondentes não encaram o homem como intermediador desse sistema. O ciclo e integração estão interligados na representação de que planta advém do solo e é a alimentação primordial para os animais.

A produção está representada com o cuidado e fertilidade do solo, "o solo não castigado", para ter qualidade do animal.

Entrevista 2: "Uhum! acho que tem que ser um solo bom, se o solo tem que ser bom pra produzi".

De acordo com Reigota (1995), a ideia de uma natureza transformada pela ação humana aparece com maior dificuldade, haja vista a impossibilidade de incorporarem espontaneamente questões que satisfaçam a totalidade do problema.

$\mathrm{Na}$ representação de um campo bom que rende mais carne por hectare, foram constatadas oito ideias centrais: campo com grande quantidade de água (16), pastagem (15), campo de várzea (12), solo macio (6), fértil (11), além de campos com menor quantidade de "pedras" (17), campo limpo e manejo adequado (8).

A maioria dos entrevistados conectou a ideia de pastagem à elevada dependência dos recursos forrageiros naturais, confirmando as pesquisas de Neske (2009) e Borba et al. (2009), que consideram umas das características marcantes da pecuária familiar.

A variação da relação entre a superfície de área útil de pastagens nativas e a superfície total de pastagens está entre 95 e 97,5\% e o alto índice de renovabilidade sempre superior a $83 \%$ independente do tipo de pecuarista familiar avaliado.

A água foi a segunda ideia mais citada, devido á dificuldade em épocas de escassez e estio já confirmados nas pesquisas de Matte (2013) e Neske (2009). O Barrocão (distrito localizado no município de Pinheiro Machado) tem grande proporção de nascentes não perenes - fluxo de água estacional

\footnotetext{
${ }^{4}$ O número situado entre parêntese está vinculado com o número de entrevistados que atribuiu esta ideia, no entanto, o entrevistado pode ter mais ideias, na mesma pergunta. Isto segue a partir deste ponto em todo o texto
}

revista brasileira educação ambiental 
(CARVALHO et al., 2015), estabelecendo um critério de vulnerabilidade, visto que são poucas nascentes perenes nessa localidade.

Essa situação confirma a preocupação da ideia de água como um critério para se ter um campo "bom" para a criação de gado. Outra ideia representada foi área de várzea e campo "macio" que supostamente foram estabelecidos por campos úmidos e argilosos, áreas baixas, vegetação rasteira, sem afloramento de rochas e solo não compactado, normalmente área apta para o arroz, atrelada a ideia de campo "limpo".

Campo macio foi representado como uma terra fértil e pastagem "boa". Essa representação foi bastante difundida pelos pecuaristas.Na verificação da percepção em relação à produtividade natural dos campos, os resultados gerados, por ordem de evocação, são seis: manejo (9), limpeza (10), adubar o solo (11), plantação de azeven (8) e clima (4).

A maioria citou quanto ao manejo, a divisão de piquetes, descanso do solo e reserva de pasto, afirmando o conhecimento empírico através da observação dos seus cotidianos, assim, atrelando a racionalidade ecológica dos pecuaristas familiares.

\section{Categoria 2: Percepção do manejo de água}

As ideias evocadas dos respondentes com relação à água no solo, por ordem de evocação: compactação do solo (11), vegetação baixa (9) e quantidade de chuva (15). A compactação do solo foi referente à fertilidade do mesmo, a vegetação foi através da falta de água e grandes enxurradas de chuva ausentam o tempo de infiltração. Há necessidade de metodologias que trabalhem essas representações em grupos de pesquisa-ação através de unidades experimentais.

Entrevista 4: "eu acho que seria assim a terra que não é fértil né".

Entrevista 8: "olha, se o campo tá muito rapado a água cai e rola tudo, se tiver mais forrado o solo, ele vai empapa mais e vai filtra".

Entrevista 24: "A gente nota quanto vem uma enxurrada de chuva muito forte, não dá tempo dá terra absorver, agora mesmo tá chovendo calma, não tem como escorrer daí vai pra baixo". 
O segundo grupo representa maneiras de armazenamento, através do campo, curva de nível, reservatórios e maneiras para a captação da água.

Entrevista 5: "ué eu penso em fazer uma curva de nível".

Entrevista 10: "daí a água té indo embora e ninguém ta aproveitando".

Entrevista 20: "que vai toda embora para o rio e vai custar a voltar".

\section{Categoria 3: Escassez da água}

$\mathrm{Na}$ categoria escassez de água foi perguntado, se pagaria e quanto se pagaria para ter água em sua propriedade, foram evocados quatro grupos distintos: os que valoram a água como um atributo de maior importância (9), este grupo mostrou agregação de valor sentimental e emocional, e possivelmente foram os que mais sofreram com a escassez de água nos últimos anos. O segundo grupo representou simbolicamente como "pagaria qualquer preço" (7), ou seja, todos representaram como condição de pagamento, valoraram de acordo com sua renda mensal e anual.

O terceiro grupo representou água como forma de bem ambiental (11), acessível e advindo da natureza, pagar pela água é algo não representado, visto que, a natureza é utilizada por todos e é gratuita. Eles, também, estabeleceram um ato de cuidado por suas cacimbas e nascentes (Figura 2).

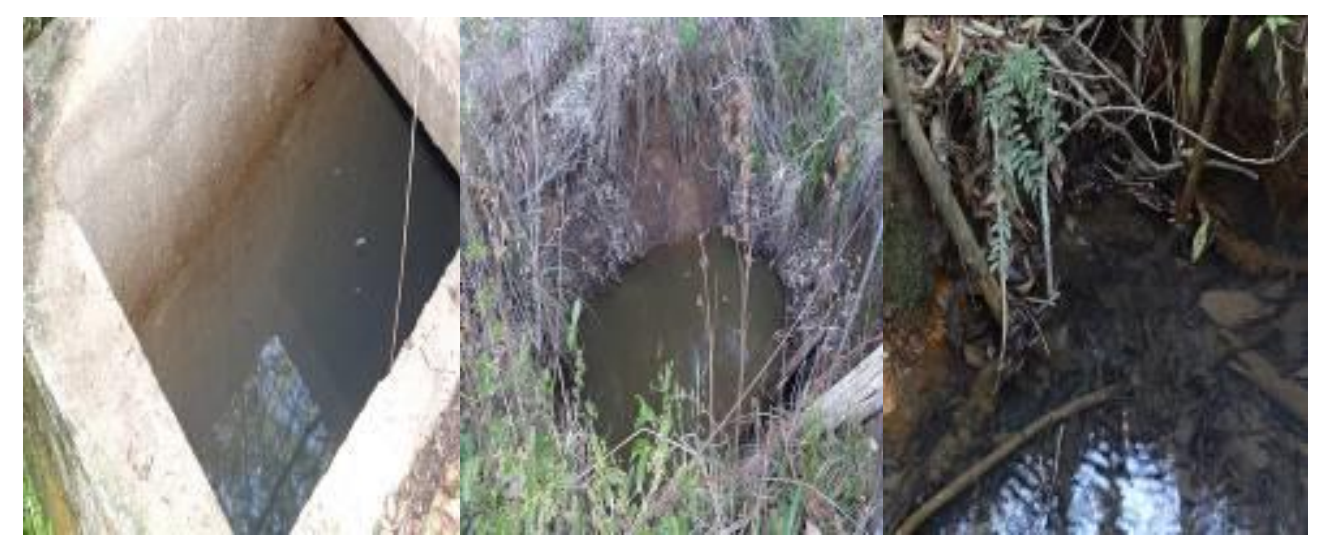

Figura 2: Os três tipos de cacimbas (nascentes) encontradas na pesquisa.

Fonte: Autores, 2019.

O quarto grupo estabeleceu contrariedade no pagamento pelo acesso à água (4) afirmaram ter água de qualidade e quantidade, visto que, moram a poucos quilômetros do Rio Barrocão.

Foi diagnosticado três tipos de nascentes (cacimbas), a primeira nascente fechada, cavada $1 \mathrm{~m} \times 1 \mathrm{~m}$, coberta. A segunda nascente cavada, 
porém, sem cobertura e estrutura, e a terceira nascente é natural, retirada a água com baldes ou por gravidade.

$\mathrm{Na}$ representação de pensamento da escassez hídrica, foram tabuladas três ideias centrais: nas quais medo (9), tristeza (11), pavor (6) e preservação (3) foram as palavras mais repetidas.

O primeiro grupo mostrou preocupação em construir fontes de água para armazenamento. $\mathrm{O}$ segundo representou o cuidado com a preservação das suas fontes naturais, e o terceiro grupo com $60 \%$ dos respondentes mostrou um sentimento de medo, tristeza, pobreza e miséria.

\footnotetext{
Entrevistado 24: "é medo né".

Entrevistado 14: "dai vem as dificuldades pra frente ne com certeza, tristeza que da na gente ve os animal passa sede".

Entrevistado 4: "Bah me vem um grande pavor, si for assim como ta indo, se agora esse inverno não chove, o verão que vem não vai ter água nem pra tomar".

Entrevistado 2: "É um pensamento ruim, pensamento ruim, chego a sonhar com essa falta de água, eu chego a sonhar com essa falta de água, de tanto agonia que sinto, não adianta né".
}

$\mathrm{Na}$ identificação de existência de obras hidráulicas e a percepção dos atos através da alteração de distribuição de água, foram relatadas três ideias distintas. Por acondicionamento de relatos, o primeiro grupo reconhece que açudes, cacimbas e bebedouros (6) podem alterar a distribuição de água da propriedade, ou seja, reconhecem que seus atos podem transformar o meio.

O segundo grupo tem recursos hídricos em suas propriedades, não encontrando necessidade de obras, açudes e bebedouros (4) e não reconhecendo a cacimba como distribuidora de água. E o terceiro grupo relatou a inexistência de qualquer tipo de distribuição de água, por motivos ambientais e monetários (14).

\section{Categoria 4: Água e qualidade de vida}

As representações de qualidade de vida com ênfase na água dos pecuaristas familiares são misturadas com sentimentos de permanência. $O$ grau de relevância nos dias atuais foi dividido em duas ideias: os pecuaristas que consideram um problema contínuo e permanente (12), principalmente pelo controle desenfreado pela procura por água e os que consideram um problema apenas para o verão (9), pelas chuvas descontínuas e carência de sistemas de captação de água. 
Foi analisado o grau de importância da água, atribuída à qualidade de vida, para analisar como é representado o grau de vulnerabilidade dos pecuaristas. As primeiras ideias representadas foram a higiene pessoal (8) e a alimentação (5).

Possivelmente é o grupo mais vulnerável, representando a escassez de água no dia-a-dia. $\mathrm{O}$ segundo grupo descreveu a água como fonte de vida e como essencial (9). O terceiro e último grupo representou a produção animal e a sede animal (11). Possivelmente, é o grupo que tem maiores problemas de distribuição de água na propriedade. Há necessidades de alternativas que impliquem na gestão ambiental e de recursos hídricos da propriedade, adotando maneiras que não causem impactos no ambiente.

\begin{abstract}
Entrevistado 5: "que a água nos faz mais falta que a luz ainda, que a água já pra inicia é a higiene do corpo da gente, o dia que não tiver agua é um horror né".

Entrevistado 10: "a água é vida pra gente ne e se tu vai fazer um alimento tu precisa da água, vai qualquer outra coisa precisa da água".
\end{abstract}

Os atores sociais representaram o surgimento da água, em ordem de evocações: nascente (8), lençol freático (6), evaporação (3), nuvens (6), rios (11) e solo (12). A maioria representou advinda do solo e da nascente. Possivelmente, é uma representação do dia-a-dia do pecuarista, visto que todos utilizam as cacimbas para abastecimento humano e grande parte para dessedentação animal.

A pecuária familiar e a paisagem do Alto Camaquã se mantêm através da agregação de fatores, onde características ambientais (terrenos declivosos e solos rasos) fornecem a bacia diversos serviços ambientais apesar dos usos. Essas características ambientais têm atuado como barreiras à modernização tecnológica produtiva do território (DADALT, 2010), e a dinâmica de manejo da pecuária familiar, baixa dependência de insumos externos, alta dependência dos recursos renováveis (BORBA; TRINDADE, 2009) com a heterogeneidade local.

A baixa interferência humana sobre os ecossistemas naturais demonstra a existência de dinâmicas produtivas específicas que são determinadas por relações construídas entre o "homem-cultural" local e a natureza (NESK, 2009). Os pecuaristas familiares representaram a experiência no campo (10), manejo (6), pastagem (11) e chuva (15) como os principais fatores de produção, retomando resultados de pesquisas anteriores sobre a baixa interferência tecnológica.

Existem soluções de manejo para que a água da chuva seja aproveitada adequadamente para a subsistência das famílias e produção pecuária. Porém, informar e educar a sociedade para um problema de dimensão universal é a 
principal dificuldade, pois grande parte dos pecuaristas familiares não acredita que possa perturbar o meio ambiente ao ponto de minimizar os recursos naturais disponíveis.

A água é fator primordial para o sustento à vida. As análises metodológicas, utilizadas a campo, contribuíram para o aprendizado de técnicas e procedimentos adotados para realizar o início de uma estratégia de educação que requer tempo e dedicação. Enfatizar os problemas de recursos hídricos na educação proporciona uma base para um pensamento sistêmico, pois a disponibilidade de água em certas regiões do Alto Camaquã é escassa ou mal gerenciada.

\section{Considerações finais}

Sato (2004) afirma que a educação ambiental deve buscar sua eterna recriação, avaliando seu próprio caminho na direção da convivência coletiva e da relação da sociedade diante do mundo.

Segundo Reigota (1995), o meio ambiente é muito mais do que os ambientes naturais que costumamos imaginar e que devemos ter uma visão globalizante de meio ambiente, que considere as relações recíprocas entre natureza e sociedade. Recomenda-se que a partir das representações, resultados e discussões deste estudo, construam-se alternativas de oficinas de educação ambiental.

Andrade et al. (1996) afirmam que as oficinas têm, por excelência, a dinâmica, a velocidade, o movimento harmônico. As oficinas educacionais seriam atreladas à pesquisa-ação, com o intuito de construção metodológica juntamente com o pecuarista e seu cotidiano.

O primeiro aspecto a se considerar é a explicação do ciclo hidrológico, capacitando os atores sociais sobre a gestão eficiente e sustentável dos recursos hídricos no âmbito da Bacia Hidrográfica do Rio Camaquã. Apesar das dificuldades, como falta de medidas estruturais e não-estruturais de educação hídrica para o consumo consciente de água das nascentes do Alto Camaquã, a única alternativa de abastecimento humano e dessedentação animal são as nascentes e a precipitação.

Posteriormente, pode-se discutir o que é Comitê de Gerenciamento da Bacia Hidrográfica do Rio Camaquã e suas atribuições a partir da bacia como unidade de gestão. Outro aspecto relevante é a importância do manejo de campo na realidade diária do pecuarista, visto que já representam como algo importante, através do processo positivo e negativo da planta, solo e animal. Existem metodologias que poderiam ser aplicadas sobre infiltração em solos com pastagem e solo descoberto.

As estratégias utilizadas podem ser voltadas à abertura de horizontes reflexivos, tentando romper com os tradicionais discursos verificados na prática educativa (CASCINO, 2007), e que associem teoria e prática. 
Grande parte dos pecuaristas pagaria para ter água em abundância em sua propriedade, em vista disso, trabalham manejo de nascentes, recuperação de áreas degradadas e fontes alternativas de armazenamento e captação de água, para diminuir a sensação e representação de medo. Como há ausência de saneamento básico e presença de fossa negra, normalmente utilizada na área rural, poderiam ser propostas unidades experimentais de sistema simplificado econômico, prático e viável de tratamento de água de uso doméstico, para a melhoria da qualidade da água destinada ao meio ambiente.

A otimização do uso das águas nas propriedades rurais é uma alternativa para os pecuaristas que são vulneráveis às mudanças climáticas, podendo retomar a estabilidade ecossistêmica do ambiente em sua propriedade. Sabe-se que a poluição pontual contribui enormemente para a poluição da água superficial (MACIEL; FARIA, 2013).

A partir das representações sociais pode-se estabelecer diversas metodologias educacionais, através dos saberes e cotidiano dos pecuaristas, já que, ninguém educa ninguém, ninguém educa a si mesmo, os homens se educam entre si, mediatizados pelo mundo (FREIRE, 1984).

É possível concluir que as representações sociais dos pecuaristas familiares do Alto Camaquã são caracterizadas pelo seu modo de vida, sentimento de medo pela escassez hídrica e outro aspecto fundamental é a importância que se dá as experiências no meio rural. De tal modo, a liberdade para escolher a melhor estratégia de educação ambiental às situações de representação, se dá com as construções de pesquisa-ação, junto com o pecuarista.

Por fim, reuniu-se elementos importantes para oferecerem subsídios nas ações de políticas públicas, extensão e pesquisa, contribuindo assim para o exercício da educação ambiental eficiente.

\section{Referências}

ANDRADE, L.; SOARES, G.; PINTO, V. Oficinas ecológicas: uma proposta de mudanças. 2.ed. Petrópolis: Vozes, 1996.

AZEVEDO, L.F.;FIALHO, M. A.V. A pecuária familiar: uma análise do modo de apropriação da natureza a partir dos saberes e práticas tradicionais - Território. In: AZEVEDO, L.F.;FIALHO, M. A.V.: A pecuária familiar do Rio Grande do Sul: história, diversidade social e dinâmicas de desenvolvimento. Org.Paulo Dabdab Waquil. Porto Alegre: Editora da Ufrgs, p 148-168, 2016.

BARDIN, L. Análise de Conteúdo. São Paulo: Edições 70, 1978.

BORBA, M. La Marginalid como potencial para laconstrucción de otro "Desarrollo": El caso de Santana da Boa Vista, Rio Grande do Sul, Brasil. Tese de Doutorado em Sociologia, Agroecologia e Desenvolvimento Sustentável, na Universidade de Córdoba, em 2002. 
BORBA, M.F.S. Desenvolvimento Territoril Endógeno: o caso do Alto Camaquã. In: BORBA, M.F.S. A pecuária familiar do Rio Grande do Sul: história, diversidade social e dinâmicas de desenvolvimento. Org.Paulo Dabdab Waquil. Porto Alegre: Editora da Ufrgs, p 187-214, 2016.

BRASIL. Lei № 9.795, de 27 de abril de 1999. Dispõe sobre a Educação Ambiental, Institui a Política Nacional de Educação Ambiental e dá outras providências.

CALLON, M. Some Elements of a Sociology of Translation: Domestication of the Scallops and the Fishermen of St Brieuc Bay. In: LAW, J. (Comp.). Power, Action and Belief.A New Sociology of Knowledge? London: Routledge\& Regan Paul, p. 196-223, 1986,

CARVALHO, C.M. A pecuária familiar e a gestão de recursos hídricos da bacia hidrográfica do Rio Camaquã: Um estudo de caso no território do Alto Camaquã. 2015. 121f. Dissertação (Mestrado em Engenharia Ambiental)Universidade Federall de Santa Maria, Santa Maria, 2016.

CARVALHO, C.M.; NUNES, D.S.; ROCHA, N.S.; CRUZ, R.C. A construção da gestão e educação ambiental dos recursos hídricos na pecuária familiar do Alto Camaquã". Revista Monografias Ambientais, v.13, n.5, p.4019-4027, 2014.

CARVALHO, C.M.; LUCAS, A.S.; ROCHA, N.S.; CRUZ, R.C.; BORBA, M.F.S. Avaliação de impacto ambiental em nascentes do Alto Camaquã a partir de uma análise multivariada. Revista Ibero-Americana de Ciências Ambientais, Aquidabã, v.6, n.1, p.202-212, 2015.

CASCINO, F. Educação Ambiental: princípios, história e formação de professores. 4. ed. São Paulo: Editora Senac São Paulo, 2007.

CPRM. Companhia de pesquisa de Recursos Minerais. Mapa Hidrogeológico do Estado do Rio Grande do Sul. Disponível em: <http://www.cprm.gov.br> Acesso em: 17.mar.2014.

CRESWELL, J. W. Projeto de pesquisa: métodos qualitativo, quantitativo e misto. Tradução Magda Lopes, 3. ed., Porto Alegre: Artmed, 2010, 296 p.

DADALT, L.P. Padrões de diversidade da vegetação lenhosa da região do Alto Camaquã, Rio Grande do Sul. Dissertação (mestrado) Programa de Pós Graduação em Ecologia, Universidade Federal do Rio Grande do Sul, 2010.

DIAS, F. G. Educação Ambiental: princípios e práticas. 9.ed. São Paulo: editora Gaia Ltda., 2004.

FRANCO, M. L. P. B. Representações sociais, ideologia e desenvolvimento da consciência. Cadernos de Pesquisa, v. 34, n. 121, p. 169-186, jan./abr. 2004.

FREIRE, P. Educação e Mudança. 8. ed. Rio de Janeiro: Paz e Terra, 1984, $79 p$.

GIL, A. C. Métodos e técnicas de pesquisa social. 5. ed. São Paulo: Atlas, 2006, 206p. 
GUARESCHI, P.; JOVCHELOVITCH, S. (Org.). Texto em representações sociais. 2. ed. Petrópolis: Vozes, 1995, p. 117-145.

GUIMARÃES, M.A formação de educadores ambientais. Campinas, São Paulo: Papirus, 2004.

LATOUR, B. Ciência em ação. São Paulo: Editora da Unesp, 2000.219p.

LEFEBVRE, H. A vida cotidiana no mundo moderno. São Paulo: Ática, 1991.

MACIEL, S. M. A.; FARIAS, E. S. O Uso e Reuso da Água nas Escolas Municipais Rurais de Santana do Livramento: Importantes Dimensões para o Desenvolvimento de Políticas Públicas. Anais do XXXVIII Encontro da ANPAD. Rio de janeiro, set. 2013.

MARINATO, C. F. Integração entre a gestão de recursos hídricos e a gestão municipal urbana: estudo da inter-relação entre instrumentos de gestão. 2008. 122f. Dissertação (Mestrado em Engenharia Ambiental) - Universidade Federal do Espírito Santo, Vitória, 2008.

MATEI, A. P.; FILIPPI, E. E. O bioma pampa e o desenvolvimento regional no Rio Grande do Sul. Encontro de Economia Gaúcha, v. 6, 2012.

MATTE, A. Vulnerabilidades, capacitações e meios de vida dos pecuaristas de corte da Campanha Meridional e Serra do Sudeste do Rio Grande do Sul. 2013, 176 f. Dissertação de Mestrado em Desenvolvimento Rural. Universidade Federal do Rio Grande do Sul, Porto Alegre, 2013.

MINAYO, M.C.S. (org.). Pesquisa social: teoria, método e criatividade.29. ed. 2004.

MOSCOVICI, S. Representações sociais: investigações em psicologia social. 8. ed. Petrópolis: Vozes, 2011. 404 p.

NESKE, M. Z. Estilos de agricultura e dinâmicas locais de desenvolvimento rural: o caso da pecuária familiar no território do Alto Camaquã do Rio Grande do Sul. 2009. 208 f. Dissertação (Mestrado em Desenvolvimento Rural) Universidade Federal do Rio Grande do Sul, Porto Alegre, 2009.

REIGOTA, M. El estado del arte de laeducacioón ambiental en Brasil. Tópicos em Educación Ambiental, México, v. 4, n.11, p. 49-62, ago., 2002.

REIGOTA, M. Meio ambiente e representação social. São Paulo: Cortez, 1995.

REIS, S.L.A.; BELLINI, M. Representações sociais: teoria, procedimentos metodológicos e educação ambiental. Acta Scientiarum Human and Social Sciences. Maringá, v. 33, n. 2, p. 149-159, 2011.

RIBEIRO, C. M. Estudo do modo de vida dos pecuaristas familiares da região da campanha do Rio Grande do Sul. 2009. 304 f. Tese (Doutorado em Desenvolvimento Rural). Programa de Pós-Graduação em Desenvolvimento Rural, Universidade Federal do Rio Grande do Sul, Porto Alegre, 2009. 
RICHARDSON, R. J. Pesquisa Social: métodos e técnicas. 3.ed. São Paulo: Atlas: 1999.

ROCHA, N.S. Efeitos do aumento da temperatura sobre a disponibilidade hídrica para a pecuária familiar na sub-bacia do Alto Camaquã, RS. 2016. 199f. Dissertação (Mestrado em Engenharia Ambiental)- Universidade Federall de Santa Maria, Santa Maria, 2016.

SATO, M. Educação Ambiental. São Carlos: RiMa, 2004.

SAUVÉ, L. Educação ambiental e desenvolvimento sustentável: uma analise complexa. Revista de Educação Pública,v. 006, n.010, jul./dez., 1997.

SEVERO, José Leonardo Rolim. Educação não escolar como campo de práticas pedagógicas. Revista Brasileira de Estudos Pedagógicos, v. 96, n. 244, 2016.

TREVISOL, J. V.; SOCOLOVSKI, M. Meio ambiente e educação ambiental: um estudo de representações sociais em professores da rede municipal de ensino de Campos Novos-SC. Revista Roteiro, v. XXIV, n. 44, p. 27-56, 2000.

TRINDADE, J.P.P.; BORBA M.F.S.; LEFEVBRE, J. Território do Alto Camaquã: apresentação da cobertura vegetal do Alto Camaquã: junho de 2007. Bagé: Embrapa Pecuária Sul, 2010, 13 p. (Embrapa Pecuária Sul. Documentos, 107). 